\title{
A study on effects of human resource architecture on organizational performance
}

\author{
Aliakbar Ahmadi ${ }^{\mathrm{a}}$, Mahdi Shahbazi ${ }^{\mathrm{b}}$ and Roghayeh Honarmand ${ }^{\mathrm{c}^{*}}$
}

\begin{abstract}
${ }^{a}$ Associate Professor Department of Management, West branch, Payamenoor University, Tehran, Iran
${ }^{b} \mathrm{PhD}$ in Human Resource Management, Research and Science Branch, Islamic Azad University, Tehran, Iran ${ }^{c}$ Associate Professor Department of Management, West branch, Payamenoor University, Tehran, Iran

C H R O N I C L E

\section{Article history:}

Received January 18, 2013

Received in revised format

8 June 2013

Accepted 10 June 2013

Available online

June 142013

Keywords:

Organizational performance

Human resource architecture

Structural equation modeling

\section{A B S T R A C T}

Measuring the performance of an organization plays an important role on development of business units. Human resource development, on the other hand, plays an important role on contributing to organizational performance. In this paper, we present an empirical study on one of Iranian industries to measure the effects of human resource architecture on organizational performance. The proposed study of this paper considers human resource architecture in terms of three factors including process, objectives and responsibilities and measures the impact of each component on organizational performance. To examine the effects of three mentioned factors, we design a questionnaire and distribute them among some experts. Structural equation modeling is implemented to examine three hypothesis of this survey. The results of the survey have confirmed the positive effects of three human resource architecture components on organization performance.
\end{abstract}

\section{Introduction}

During the past few years, there have been tremendous efforts on measuring the effects of various factors on organizational performance. Sadeghi (2011), for instance, studied the relationship between the alignments of different typologies of strategies for organizational change strategies including structure, technology, culture, human resources, and goals with improving the performance. They reported that the more the alignment among the typologies of organizational change strategies increases regardless of their group including high performance, medium performance, and low performance, the more their performance improves. They also reported that the more the alignment among the typologies of organizational change strategies increases in a specific group, the more their own performance improves. Walumbwa et al. (2011) investigated the link between ethical leadership and performance using information from the People's Republic of China. They tested leader-member exchange (LMX), self-efficacy, and organizational identification as mediators of the ethical leadership 
to performance relationship and the results were consistent with social exchange, social learning, and social identity theories.

García-Morales et al. (2007) investigated the effects of personal mastery on organizational performance, both directly and indirectly through the dynamic capabilities of organizational learning and innovation. They reported that in both kinds of firms: first, personal mastery affects organizational performance directly and indirectly through organizational learning and innovation; second, organizational learning impacts organizational performance positively, both directly and indirectly through organizational innovation and finally, organizational innovation impacts organizational performance positively. According to Harris and Ogbonna (2001), research emerging from various fields of organizational analysis has built a linkage between market orientation and strategic human resource management (SHRM) to organizational performance. They recommended a direct link between market orientation and performance and indicate that the association between SHRM and performance is mediated by the extent of market orientation exhibited by the organization.

Jacobs et al. (2013) examined the relationship between senior management team culture and organizational performance in some hospitals. They used a validated culture rating instrument, the Competing Values Framework, to measure senior management team culture. They also investigated the associations between organizational culture and performance based on ordered probit and multinomial logit models. They reported that organizational culture varies across hospitals and over time, and this variation was at least in part related to consistent and predictable ways with different organizational characteristics and routine measures of performance. Meftahi et al. (2012) performed an empirical investigation to measure the indirect impact of e-business on organizational performance. The proposed study of this paper designs a questionnaire and distributes it among 40 professional experts in various industries in province of Ilam, Iran. The survey examines four hypothesis for a possible correlation between e-business and integrated suppliers, e-business and customers, integrated customers and suppliers with organizational performance. The results of this survey confirm a positive relationship between all these components either directly or indirectly.

Farkhani et al. (2013) investigated the effect of ethical climate on turnover intentions and organizational performance based on the implementation of various techniques. The interview technique was implemented to detect the factors of input and output. Required data were collected to measure performance of firms based on some documents. The survey method was implemented to study the ethical climate and turnover intentions and the effect of ethical climate on turnover intentions and organizational performance was evaluated.

\section{The proposed study}

In this paper, we present an empirical study on one of Iranian industries to measure the effects of human resource architecture on organizational performance. The proposed study of this paper considers human resource architecture in terms of three factors including process, objectives and responsibilities and measures the impact of each component on organizational performance. Fig. 1 demonstrates the proposed study of this paper as follows,

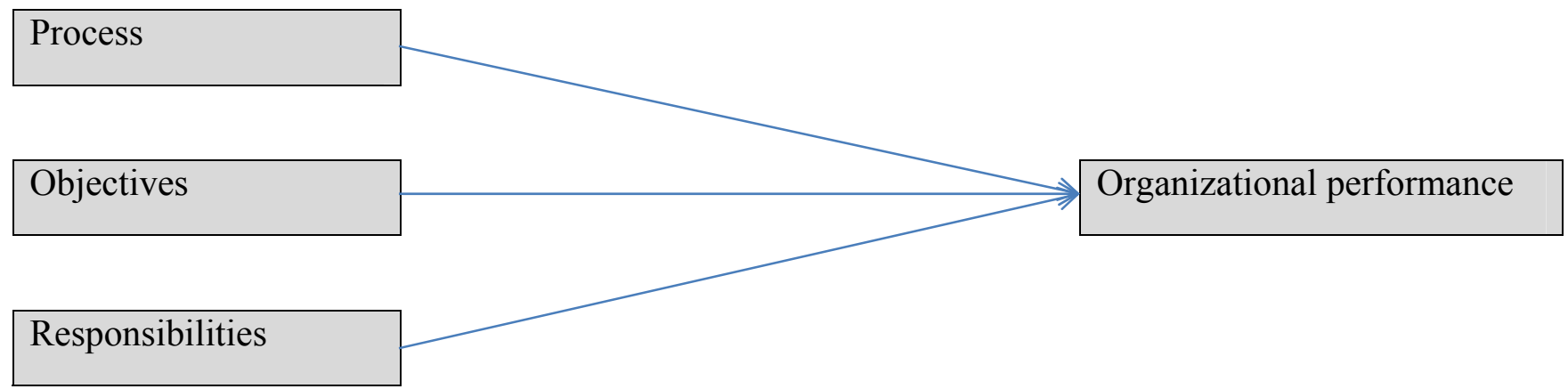

Fig. 1. The proposed study 
To examine the effects of three mentioned factors, we design a questionnaire and distribute them among some experts who work for some Iranian industries. The sample size is calculated as follows,

$$
N=Z_{\alpha / 2}^{2} \frac{p \times q}{e^{2}},
$$

where $N$ is the sample size, $p=1-q$ represents the probability, $z_{\alpha / 2}$ is CDF of normal distribution and finally $\varepsilon$ is the error term. For our study we assume $p=0.5, z_{\alpha / 2}=1.96$ and $e=0.99$, the number of sample size is calculated as $N=267$. In this study, we have distributed 300 questionnaires among some the sample size. Structural equation modeling is implemented to examine three hypothesis of this survey. The proposed study examines the following three hypotheses,

1. Human resource processes influence organizational performance, positively.

2. Human resource objectives influence organizational performance, positively.

3. Human resource responsibilities influence organizational performance, positively.

To examine, three hypotheses of this survey, we have used structural equation modelling (SEM). The study uses different statistics to verify the proposed hypotheses and Table 1 summarizes the results of our survey.

\section{Table 1}

The summary of statistics SEM implementation

\begin{tabular}{lll}
\hline Index & Results & Desirable \\
\hline Chi-Square/df & 2.231 & $1-3$ \\
RMR & 0.034 & $<0.05$ \\
GFI & 0.915 & $>0.90$ \\
AGFI & 0.936 & $>0.90$ \\
RMSEA & 0.083 & $<0.10$ \\
CFI & 0.910 & $>0.9$ \\
IFI & 0.902 & $>0.9$ \\
NFI & 0.963 & $>0.0$ \\
\hline
\end{tabular}

As we can observe from the results of Table 1, all statistical observations are remained within the acceptable limits and we can confirm the overall performance of the proposed model.

\section{The results}

In this section, we present details of our findings on testing various hypotheses of this survey. Fig. 2 and Fig. 3 show details standard values and t-student values for testing the hypotheses of the survey.

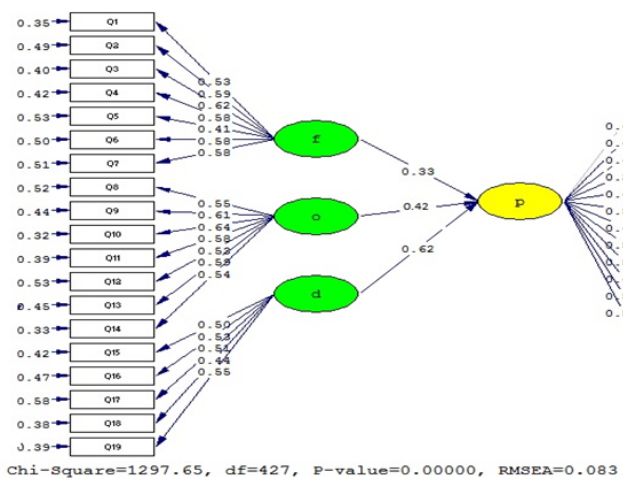

Fig. 2. The summary of standard values

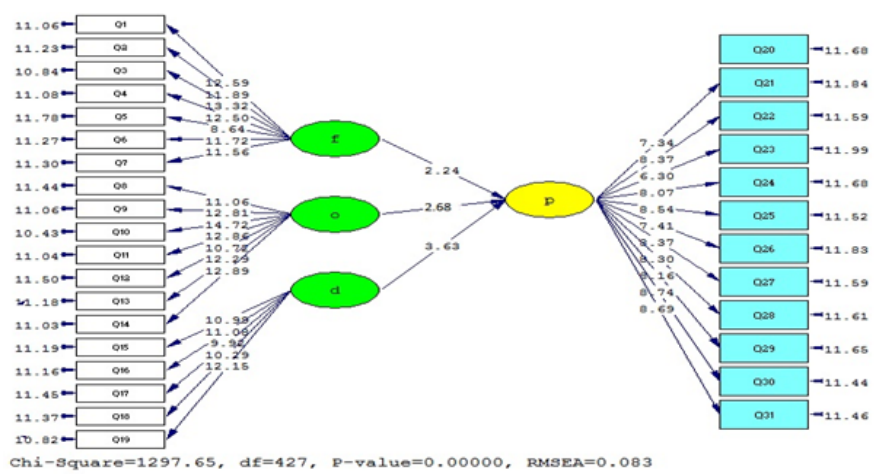

Fig. 3. The summary of t-student values 
The results of standard values indicate that all three factors influence organizational performance, positively. All t-student values are significance when $\alpha=5 \%$. Therefore, we can conclude that organization process, objectives and responsibilities all together influence organizational performance, significantly.

\section{Conclusion}

In this paper, we have presented an empirical investigation to study the impacts of three organizational architectures including process, objectives as well as responsibilities. The proposed study of this paper has designed a questionnaire and distributed among some Iranian experts who worked for various industries. The study has implemented structural equation modelling and confirmed all three hypotheses of this survey. Table 2 shows details of our findings.

\section{Table 2}

The summary of testing various hypotheses of the survey

\begin{tabular}{llllllll}
\hline Hypothesis & & & Coefficient & t-value & Sig. & Result \\
\hline $\begin{array}{l}\text { Human resource processes influence } \\
\text { positively. }\end{array}$ & & 0.33 & 2.62 & 0.000 & Confirmed \\
$\begin{array}{l}\text { Human resource } \\
\text { positively. }\end{array}$ & & & & & & & \\
$\begin{array}{l}\text { Human resource responsibilities influence } \\
\text { positively. }\end{array}$
\end{tabular}

The results of t-student values are all meaningful when the level of significance is $\alpha=5 \%$.

\section{References}

Farkhani, Z., Armoun, Z \& Javidnia, M. (2013). The impact of ethical climate on turnover intentions and organizational performance. Management Science Letters, 3(6), 1575-1582.

García-Morales, V.J., Lloréns-Montes, F.J., \& Verdú-Jover, A.J. (2007). Influence of personal mastery on organizational performance through organizational learning and innovation in large firms and SMEs. Technovation, 27(9), 547-568.

Harris, L.C., \& Ogbonna, E. (2001). Strategic human resource management, market orientation, and organizational performance. Journal of Business Research, 51(2), 157-166.

Jacobs, R., Mannion, R., Davies, H.T.O., Harrison, S., Konteh, F., \& Walshe, K. (2013). The relationship between organizational culture and performance in acute hospitals. Social Science \& Medicine, 76, 115-125.

Meftahi, H., Nazeri, A \& Nosratpour, M. (2012). An empirical study to measure the impact of ebusiness on organizational performance with an emphasis on integrated production information. Management Science Letters, 2(5), 1755-1760.

Sadeghi, D.(2011). Alignment of organizational change strategies and its relationship with increasing organizations' performance. Procedia - Social and Behavioral Sciences, 20, 1099-1107.

Walumbwa, F.O., Mayer, D.M., Wang, P., Wang, H., Workman, K., Christensen, A.L.(2011). Linking ethical leadership to employee performance: The roles of leader-member exchange, selfefficacy, and organizational identification. Organizational Behavior and Human Decision Processes, 115(2), 204-213. 